\title{
Combined Effect of Syzygium cumini Seed Kernel Extract with Oral Hypoglycemics in Diabetes Induced Increase in Susceptability to Ulcerogenic Stimuli
}

\author{
Anoosha Jonnalagadda*, Karthik K Maharaja and Prem Kumar N
}

Department of Pharmacology, Krupanidhi College of Pharmacy, India

\begin{abstract}
Diabetes has been reported to increase propensity to peptic ulceration through its effect both on offensive and defensive mucosal factors. Seeds of Syzygium cumini have been reported to have both antidiabetic as well as ulcer protective effects. The present study evaluated the antidiabetic effects of ethanolic extract of dried seed kernel of Syzygium cumini $(200 \mathrm{mg} / \mathrm{kg})$ and its comparative effect on gastric ulceration with standards Acarbose $(5 \mathrm{mg} / \mathrm{kg})$ an a-glucosidase inhibitor and natural standard Quercetin $50 \mathrm{mg} / \mathrm{kg}$ and $100 \mathrm{mg} / \mathrm{kg}$. The study also investigated the combined effect of Syzygium cumini seed kernel extracts with oral hypoglycemic agents in diabetes induced ulcer. The development of diabetic ulcers was assessed biochemically. Diabetes was induced by high fat diet/low dose streptozotocin $(35 \mathrm{mg} / \mathrm{kg})$. The protective effects of Syzygium cumini in rats with type 2 diabetes mellitus were investigated by oral glucose tolerance test. Single and repeated dose study was performed in normal and diabetic rats. Diabetic rats were exposed to gastric ulceration by indomethacin and ethanol induced models to study the role of oral hypoglycemics in diabetes induced increase in susceptibility to ulcerogenic stimuli. Syzygium cumini and its combination with standard showed significance in reducing the elevations of gastric ulcer index in the induced models and restored the depleted antioxidant defenses (superoxide dismutase, catalase and total proteins activities) caused by indomethacin administration. It was concluded that Syzygium cumini along with Acarbose represents a potential therapeutic option to reduce the risk of Diabetes induced gastric ulcerogenic stimuli in type 2 diabetic patients.
\end{abstract}

Keywords: Diabetes; Gastric ulcer; Syzygium cumini; Acarbose; Quercetin

\section{Introduction}

Acute gastric inflammation and ulcer disease occur with high prevalence in patients with type 2 diabetes mellitus, and are strongly correlated with the duration of diabetes. Also, peptic ulcers related to diabetes mellitus are more severe with slow healing rate and often associated with complications such as gastrointestinal bleeding [1,2]. However, little attention has been paid to the incidence and healing rate of peptic ulcer in diabetes because peptic ulcers among diabetics are considered infrequent [3]. Previous studies demonstrated that streptozotocin-diabetic animals have increased vulnerability of the gastric mucosa to various ulcerogens such as ischemia/reperfusion, stress, ethanol and non steroidal anti-inflammatory drugs [4-7]. The mechanism underlying the increased susceptibility of gastric mucosa in diabetic animals is multi factorial and includes alteration of gastric motility [8], impairment of duodenal bicarbonate secretion [9], attenuation of angiogenesis and dysfunction of capsaicin sensitive neurons involved in the protection of gastric mucosa [10]. However, increased production of reactive oxygen species and pro inflammatory cytokines seems to play a major role [7,11-13]. Antiulcer evaluation was done by using Indomethacin and ethanol induced ulcers in experimental animals.

Syzygium cumini also called Eugenia jambolana (EJ) has been reported to have hypoglycemic effects both in experimental models and clinical studies. EJ seed apart from hypoglycemic activity has been reported to have anti-inflammatory [14], neuropsychopharmacological, antibacterial [15], anti-oxidant [16] and antidiarrhoeal effects [17]. EJ seed kernel decreased the oxidative stress in diabetic rats, which in turn may be due to its hypoglycemic property. Reported the ulcer protective effect of ethanolic extract of $\mathrm{E}$. jambolana seeds (EJE) and the effect seemed to be due to its predominant action on mucosal defensive factor and antioxidant effect [18].

This was encouraging to conduct the present study in order to evaluate the protective effects of the EJE alone and in combination with Acarbose in rats with type 2 diabetes mellitus exposed to models which cause ulcerogenic stimuli. To study the role of oral hypoglycemics in diabetes induced increase in susceptibility to ulcerogenic stimuli and the effect of Syzgium cumini seed kernel extract on antioxidant defense status in stomach homogenate with the selected dose of $200 \mathrm{mg} / \mathrm{kg} /$ day as per Aditi Chaturvedi [18]. Quercetin used as natural standard for comparing anti ulcer property, as our intension is with the use of only one synthetic drug, decrease the progression of complication Diabetes induced ulcers. So Syzgium cumini was compared with quercetin in treating ulcers. Also the possible results underlying these protective effects were investigated.

\section{Methods}

The experimental protocol used in the present study was approved

*Corresponding author: Anoosha Jonnalagadda, Krupanidhi College of Pharmacy, No.12/1, Chikkabellandur, Carmelram Road and Post, Varthur Hobli, Bangalore 560035, Karnataka, India, Tel: 0863-2235012; E-mail: anu.ananya789@gmail.com

Received November 11, 2012; Accepted December 14, 2012; Published December 19, 2012

Citation: Jonnalagadda A, Maharaja KK, Prem Kumar N (2013) Combined Effect of Syzygium cumini Seed Kernel Extract with Oral Hypoglycemics in Diabetes Induced Increase in Susceptability to Ulcerogenic Stimuli. J Diabetes Metab 4: 236 doi:10.4172/2155-6156.1000236

Copyright: (c) 2013 Jonnalagadda A, et al. This is an open-access article distributed under the terms of the Creative Commons Attribution License, which permits unrestricted use, distribution, and reproduction in any medium, provided the original author and source are credited. 
Citation: Jonnalagadda A, Maharaja KK, Prem Kumar N (2013) Combined Effect of Syzygium cumini Seed Kernel Extract with Oral Hypoglycemics in Diabetes Induced Increase in Susceptability to Ulcerogenic Stimuli. J Diabetes Metab 4: 236. doi:10.4172/2155-6156.1000236

Page 2 of 6

by the institutional Animal Ethical committee. Male Sprague dawley rats weighing between 200-250 g were employed in the present study. They were housed in standard propylene cages (three rats/cage) and maintained under controlled room temperature $\left(22 \pm 2^{\circ} \mathrm{C}\right)$ and $55 \pm$ $5 \% \mathrm{RH}$ with $12: 12 \mathrm{~h}$ light and dark cycle. All rats were provided with normal pellet diet (Amrut diet, New Delhi) with water ad libitum prior to the dietary manipulation.

\section{Development of high fat diet-fed/low dose streptozotocin treated type 2 diabetic rats}

The animals were fed high fat diet (HFD), once a day for 2 weeks followed by IP injection of streptozotosin $(35 \mathrm{mg} / \mathrm{kg})$ dissolved in 1 $\mathrm{M} / \mathrm{L}$ citrate buffer ( $\mathrm{pH}$ 4.4) after overnight fasting. Blood sample was collected from tail vein and glucose was measured using glucose diagnostic kit (Accucheck, India). The rats with non fasting plasma glucose level of $\geq 300 \mathrm{mg} / \mathrm{dl}$ will be considered diabetic [19].

\section{Experimental design}

The rats were randomly divided into six equal groups ( $\mathrm{n}=6$, each). The first group was the non-diabetic rats, receives saline and vehicle and served as control. All the remaining groups were diabetic rats. Second group was diabetic control. The animals of the third group received oral $200 \mathrm{mg} / \mathrm{kg} /$ day of ethanolic extract of Syzygium cumini seed kernel (SCSE) [18]. Fourth group treated with Quercetin 50 and $100 \mathrm{mg} / \mathrm{kg} /$ day [20]. Fifth group Acarbose $5 \mathrm{mg} / \mathrm{kg} /$ day [21] group six SCSE+ Acarbose low dose were given. Drug solution and extract were freshly prepared and administered for a period of 8 weeks.

Oral glucose tolerance test: The animals were fasted for $12 \mathrm{~h}$ and then orally administered with $2.0 \mathrm{~g} / \mathrm{kg}$ glucose. Blood glucose levels were measured at 0, 30, 60 and $120 \mathrm{~min}$ after glucose load [19].

\section{Single and Repeated dose study in normal and diabetic rats:}

- Single dose study: Normal and diabetic rats will be administered with a single dose of Syzygium cumini seed kernel extract and the selected oral hypoglycemic agents (OHA). The blood glucose level will be estimated just prior to the administration of Syzygium cumini and OHA and at 1,2 and $4 \mathrm{~h}$ after administration. Glucose levels will be estimated using glucose diagnostic kit (Accucheck, India).

- Repeated dose study: The same groups (Single dose study) of normal and diabetic animals will be continued with the same dose levels of Syzgium cumini and OHA once daily, for 11 days. The glucose levels of all the animals will be measured on $3^{\text {th }}, 5^{\text {th }}$, $7^{\text {th }}, 9^{\text {th }}$ and $11^{\text {th }}$ day of the treatment period [22].

\section{Anti ulcer evaluation will be done by following models in experimental animals}

Healing of indomethacin induced gastric ulcers, a model to study free radical scavenging activity: The gastric ulcers will be induced by administering indomethacin ( $5 \mathrm{mg} / \mathrm{kg} . \mathrm{p} . \mathrm{o})$ for 5 days to the normally fed rats. The animals were then treated with the drug for 5 days after induction of ulcer while the control group will receive only vehicle. The last dose of indomethacin will be considered as $0^{\text {th }}$ day. Rats will be sacrificed on the same day. The stomach will be removed; ulcer score and ulcer index will be determined [23]. The glandular portion of the stomach will be used for the estimation of mucin content [24], total proteins [25] antioxidant factors like superoxide dismutase activity [26], and catalase activity [27]
The number of ulcers is noted and the severity is recorded with the following scores:

$0=$ no ulcer, 1 =superficial ulcer, $2=$ deep ulcers, $3=$ perforation.

\section{- Evaluation}

An ulcer index $U I$ is calculated by the formula: $U I=U \mathrm{~N}+U S+$ $U \mathrm{P}^{\star} 10^{-1}$

$U N=$ average of number of ulcers per animal, US=average of severity score, $U \mathrm{P}=$ percentage of animals with ulcers [28].

Ethanol induced gastric ulcers: Albino rats will be fasted for 36 $\mathrm{h}$ before administration of $90 \%$ ethanol $(1 \mathrm{ml} / 200 \mathrm{gm})$. The drug will be administered $1 \mathrm{~h}$ before ethanol administration. One hour after ethanol administration, the animals will be sacrificed, stomach will be isolated and ulcer index will be determined [29].

\section{Estimation of antioxidants in tissue homogenate}

Preparation of stomach homogenate: At the end of each experiment, the stomach was homogenized in $20 \mathrm{ml}$ of cold $0.1 \mathrm{~N}$ perchloric acid containing $16.8 \mathrm{mg}$ of disodium EDTA and $50 \mathrm{nmol}$ of isopropyl homocholine as an internal standard, using a homogenizer. The homogenate was centrifuged for $20 \mathrm{~min}$ with $10,000 \mathrm{rpm}$ at $48^{\circ} \mathrm{C}$.

Determination of gastric mucin content: Adherent gastric glandular mucous was measured by the method of Ajeigbe et al. [30] The excised stomach was soaked for $2 \mathrm{~h}$ in $0.1 \%$ alcian blue dissolved in buffer solution containing $0.1 \mathrm{M}$ sucrose and $0.05 \mathrm{M}$ sodium acetate ( $\mathrm{pH}$ adjusted to 5.8 with hydrochloric acid). After washing the stomach twice in $0.25 \mathrm{M}$ sucrose (15 and $45 \mathrm{mins}$ ), the dye complexed with mucous was eluted by immersion in $10 \mathrm{ml}$ aliquots of $0.5 \mathrm{M} \mathrm{MgCl}_{2}$ for 2 $\mathrm{h}$. The resulting blue solution was shaken with equal volumes of diethyl ether, and optical density of the aqueous phase was measured at 605 $\mathrm{nm}$ using a spectrophotometer. Using a standard curve, the absorbance of each solution was then used to calculate the concentration of the dye and its weight (expressed in $\mathrm{mg}$ ). The weight of the dye was then expressed over the weight of the stomach.

Estimation of total proteins: Protein concentration was estimated according to the Lowry's method [25], using bovine serum albumin (BSA) as a standard.

Measurement of superoxide dismutase (SOD) and catalase activity: Stomach homogenate was centrifuged $17,500 \mathrm{~g}$ at $4^{\circ} \mathrm{C}$, for 10 min. The supernatant was used for the measurement of SOD activity by hematoxylin auto oxidation method [31] and catalase activity by $\mathrm{H}_{2} \mathrm{O}_{2}$ degradation method [32].

\section{Statistical analysis}

All the data are expressed as mean \pm SEM. Comparisons among the groups were analyzed with one way ANOVA followed by Tukey's multiple comparison test. The $P$ value of less than 0.05 was considered to be statistically significant.

\section{Drugs and chemicals}

Streptozotocin was obtained from sigma-Aldrich Ltd., St. Louis, USA and quercetin from Himedia labouratories, Bombay, India. Fructose was purchased from El-Nasr Chemical Co., Abou Zaabal, Cairo, Egypt. The extract of Syzygium cumini seed kernel was collected from the Green chem. industry, Bangalore. All other chemicals used in the present study were of analytical grade (Figures 1 and 2). 
Citation: Jonnalagadda A, Maharaja KK, Prem Kumar N (2013) Combined Effect of Syzygium cumini Seed Kernel Extract with Oral Hypoglycemics in Diabetes Induced Increase in Susceptability to Ulcerogenic Stimuli. J Diabetes Metab 4: 236. doi:10.4172/2155-6156.1000236

Page 3 of 6

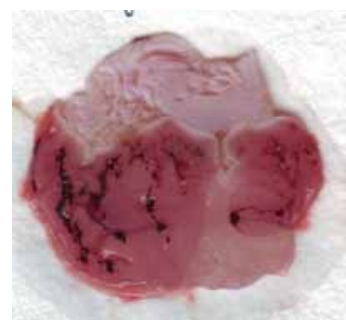

Diabetic control

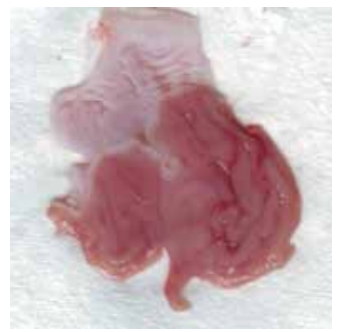

SCSE treated

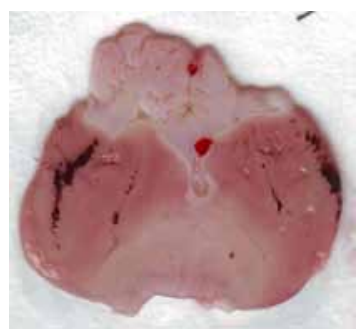

Acarbose treated

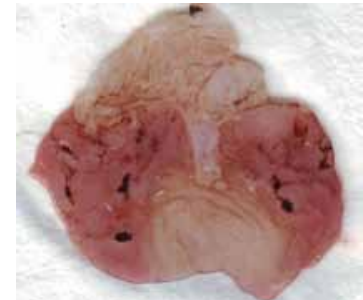

Normal control

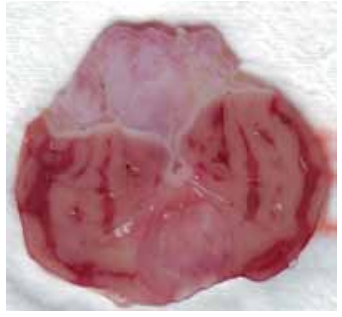

Quercetin $50 \mathrm{mg}$ treated

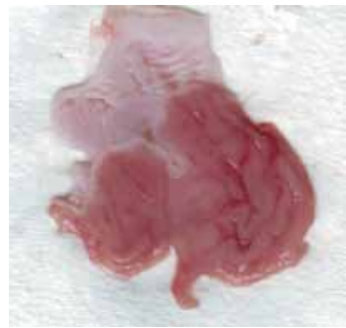

QE $100 \mathrm{mg}$ treated

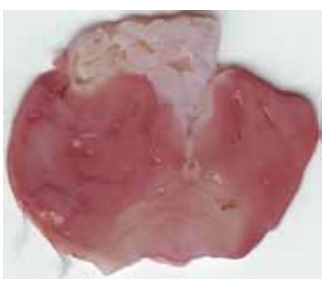

SCSE + Acarbose treated

Figure 1: Gross appearance of the Ulcers in Stomachs of different groups - Indomethacin model.

\section{Results}

Effect of S. cumini seed kernel extract on blood glucose levels in normal and diabetic animals (single and multiple dose study)

After the $2^{\text {nd }}$ week of STZ injection, diabetic rats showed significant increase in blood glucose levels than control rats where as normal rats treated with S. cumini seed kernel extract showed decrease in blood glucose level (14.28\%) until $2 \mathrm{~h}$ in single dose study. Multiple dose study exhibited a significant reduction (28.6-34.2\%) in blood glucose level between $9^{\text {th }}$ and $11^{\text {th }}$ day.
Diabetic rats with single dose of the extract exhibited decrease (14.68\%) in blood glucose level until $4 \mathrm{~h}$ and then tended to increase and multiple doses showed significant reduction (37.6-40.7\%) in blood glucose level between $7^{\text {th }}$ and $11^{\text {th }}$ day.

\section{Effect of SCSE on oral glucose tolerance test in diabetic rats}

In Glucose fed rats $(2 \mathrm{~g} / \mathrm{kg})$, the percentage reduction in blood glucose levels in $2 \mathrm{~h}$ was extremely significant with groups treated with SCSE (8.81\%) alone and in combination with Acarbose (12.7\%) when compared to diabetic control group (Table 1).

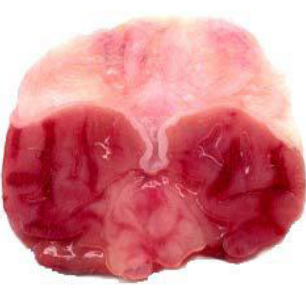

Diabetic control

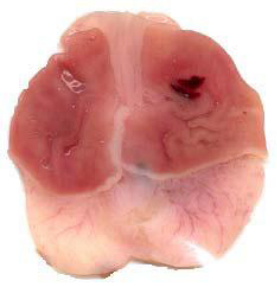

SCSE treated

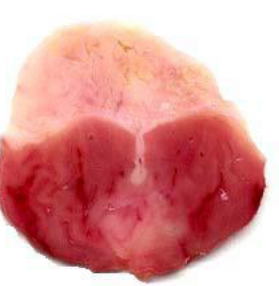

QE $50 \mathrm{mg}$ treated

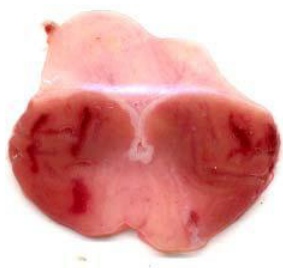

Normal control

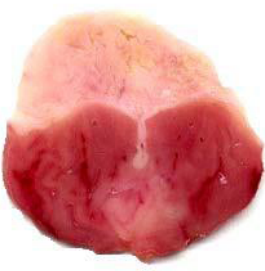

Acarbose treated

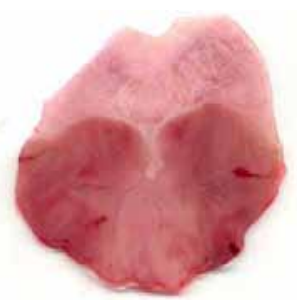

QE $100 \mathrm{mg}$ treated

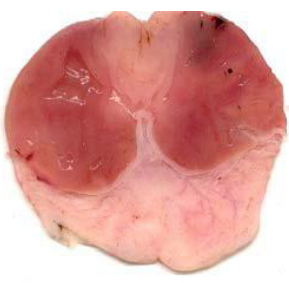

Acarbose + SCSE treated

Figure 2: Gross appearance of the Ulcers in Stomachs of different groupsEthanol model. 
Citation: Jonnalagadda A, Maharaja KK, Prem Kumar N (2013) Combined Effect of Syzygium cumini Seed Kernel Extract with Oral Hypoglycemics in Diabetes Induced Increase in Susceptability to Ulcerogenic Stimuli. J Diabetes Metab 4: 236. doi:10.4172/2155-6156.1000236

\section{Effect of SCSE, QE and Acarbose in stomach homogenate on SOD and catalase activity}

Stomach homogenate SOD activity was significantly $(p<0.05)$ low in 10 weeks diabetic rats as compared to age matched non-diabetic rats. Eight weeks treatment with SCSE, QE and Acarbose significantly $(p<0.05)$ restored SOD activity to normal. There was a significant effect of drugs in control rats after 8 weeks of treatment (Table 1).

Stomach homogenate catalase was significantly $(p<0.05)$ high in 10 weeks diabetic rats as compared to age matched non-diabetic rats. Eight weeks treatment with drugs significantly $(p<0.05)$ reverted catalase activity to control values. However when compared to individual drugs, the combination A+SCSE group showed SOD and Catalase values nearest to normal which shows its effectiveness (Table 2).

\section{Measurement of anti ulcer activity in indomethacin and ethanol induced ulcer models}

When compared to other groups, SCSE and QE $100 \mathrm{mg}$ are shown to have significant results $(p<0.05)$ in ulcer index and ulcer score when compared to diabetic control. Among which the combination Acarbose+ SCSE is effective than other groups showing significance $(p<0.001)$ for both indomethacin and ethanol ulcer models (Table 3; Chart 1).

\section{Discussion}

Metabolic syndrome is characterized by a cluster of pathological changes including obesity, hyper-triglyceridemia, impaired glucose tolerance and insulin resistance. A modified diet (fructose diet) was adopted to induce insulin resistance because the role of fructose in the development of diabetic complications was well documented $[33,34]$ and injection of a single dose of STZ induced diabetic state is similar to pre-diabetic insulin resistant state in humans [35]. The complication rate and the severity of complications increase as the duration of diabetes increases [36].

Several reports indicated that diabetes mellitus increases the mucosal susceptibility to ulcerogenic stimuli and predisposition to gastric ulceration mainly in NIDDM. The mechanism by which Diabetes induces ulcer is by the loss of pain sensation can result in development of ulcer that heel poorly because of diffuse vascular injury in diabetes and are a major cause of morbidity. Visceral autonomic neuropathy is the most important underlying factor among which is caused due to increase of free radicals [37]. In such conditions of co-occurring diabetes and gastric ulcers, it would be better to manage with drugs that have both anti-diabetic and anti-ulcer activities. This would be cost effective as well as incidences of adverse effects can be minimized.

In our present study taken, Syzygium cumini reflects its pharmacological importance in its antioxidant property of Tannins in 1,1-diphenyl-2-picrylhydrazyl (DPPH) radical scavenging activity and ferric reducing/antioxidant power (FRAP) and thus gastro protective and anti ulcerogenic property [18]. It also shows anti diabetic activity by its effectiveness in inhibiting maltase when compared to the Acarbose control. Therefore the possible mechanism by which this herb acts as an anti-diabetic agent is by inhibiting alpha-glucosidase enzyme [38] Acarbose, an oral hypoglycemic agent and Quercetin natural drug [39] shows similar alpha-glucosidase enzyme inhibiting action thus selected as standard drugs for the study.

\begin{tabular}{|c|c|c|c|c|}
\hline Time & $0 \mathrm{~min}$ & $30 \mathrm{~min}$ & $60 \mathrm{~min}$ & $120 \mathrm{~min}$ \\
\hline NC & $90 \pm 1.3$ & $\begin{array}{l}126 \pm 1.2 \\
(\uparrow 40.0 \%)\end{array}$ & $\begin{array}{l}117 \pm 1.4 \\
(\uparrow 30.0 \%)\end{array}$ & $\begin{array}{l}93 \pm 0.9 \\
(\uparrow 3.33 \%)\end{array}$ \\
\hline DC & $234 \pm 1.9$ & $\begin{array}{l}295 \pm 2.26 \\
(\uparrow 26.06 \%)\end{array}$ & $\begin{array}{l}291 \pm 1.5 \\
(\uparrow 24.35 \%)\end{array}$ & $\begin{array}{l}287.4 \pm 2.6 \\
(\uparrow 22.64 \%)\end{array}$ \\
\hline Acarbose & $179.2 \pm 0.8$ & $\begin{array}{l}208.9 \pm 1.6 \\
(\uparrow 16.57 \%)^{\mathrm{a}}\end{array}$ & $\begin{array}{l}222 \pm 1.02 \\
(\uparrow 23.88 \%)^{a}\end{array}$ & $\begin{array}{l}186.1 \pm 0.8 \\
(\uparrow 3.85 \%)^{\mathrm{a}}\end{array}$ \\
\hline QE $50 \mathrm{mg}$ & $166.3 \pm 0.9$ & $\begin{array}{l}212.6 \pm 1.09 \\
(\uparrow 27.84 \%)^{\mathrm{a}}\end{array}$ & $\begin{array}{l}239.9 \pm 0.9 \\
(\uparrow 44.25 \%)^{\mathrm{a}}\end{array}$ & $\begin{array}{l}196.1 \pm 0.78 \\
(\uparrow 17.91 \%)^{\mathrm{a}}\end{array}$ \\
\hline QE $100 \mathrm{mg}$ & $183.3 \pm 0.6$ & $\begin{array}{l}212.6 \pm 1.05 \\
(\uparrow 15.98 \%)^{\mathrm{a}}\end{array}$ & $\begin{array}{l}248.3 \pm 0.76 \\
(\uparrow 35.46 \%)^{\mathrm{a}}\end{array}$ & $\begin{array}{l}189.9 \pm 1.5 \\
(\downarrow 3.6 \%)^{\mathrm{a}}\end{array}$ \\
\hline S. cumini seed kernel extract & $209.1 \pm 1.4$ & $\begin{array}{l}241.5 \pm 0.6 \\
(\uparrow 15.49 \%)^{\mathrm{a}}\end{array}$ & $\begin{array}{l}261.6 \pm 0.56 \\
(\uparrow 25.10 \%)^{\mathrm{a}}\end{array}$ & $\begin{array}{l}192 \pm 0.96 \\
(\downarrow 8.18 \%)^{\mathrm{a}}\end{array}$ \\
\hline $\begin{array}{l}\text { Acarbose+S.cumini } \\
\text { Seed kernel extract }\end{array}$ & $195.5 \pm 2.1$ & $\begin{array}{l}227.7 \pm 0.76 \\
(\uparrow 6.47 \%)^{a}\end{array}$ & $\begin{array}{l}236 \pm 0.11 \\
(\uparrow 20.71 \%)^{\mathrm{a}}\end{array}$ & $\begin{array}{l}180.1 \pm 0.7 \\
(\downarrow 12.77 \%)^{\mathrm{a}}\end{array}$ \\
\hline
\end{tabular}

All values are mean $\pm \mathrm{SEM}, \mathrm{n}=6,{ }^{\mathrm{a} P}<0.0001,{ }^{\mathrm{b}} \mathrm{P}<0.001,{ }^{\mathrm{c}} \mathrm{P}<0.05$ when compared to Diabetic control (DC) group

Table 1: Effect of Syzygium cumini seed kernel extract with Acarbose in OGTT (mg/dl) - Diabetic Rats.

\begin{tabular}{|c|c|c|c|c|}
\hline Parameter & Mucin content & Total proteins & SOD & CATALASE \\
\hline NC & $0.89 \pm 0.14$ & $22.5 \pm 1.7$ & $24.3 \pm 1.58$ & $20.3 \pm 0.11$ \\
\hline D.C & $0.09 \pm 0.024^{* *}$ & $8.7 \pm 0.83^{* * *}$ & $8.08 \pm 0.17^{* * *}$ & $4.56 \pm 0.29^{a * * *}$ \\
\hline QE $50 \mathrm{mg}$ & $0.24 \pm 0.43^{*}$ & $14.6 \pm 0.62^{a \star \star \star}$ & $15.75 \pm 1.2^{a \star \star *}$ & $10.05 \pm 0.09^{a * *}$ \\
\hline Acarbose & $0.11 \pm 0.3^{* *}$ & $11.3 \pm 1.1^{* \star *}$ & $10.1 \pm 0.55^{\star \star *}$ & $8.7 \pm 0.14^{\mathrm{a} \star \star \star}$ \\
\hline S. cumini seed kernel extract & $0.31 \pm 0.09^{*}$ & $16.8 \pm 1.2^{a \star *}$ & $17.1 \pm 0.8^{a \star \star}$ & $13.4 \pm 0.18^{\mathrm{a} * * *}$ \\
\hline
\end{tabular}

Results are Mean \pm SEM of 6 rats in each group. One-way ANOVA followed by Tuckey's test for multiple comparisons was applied for comparing the Parameters with $\mathrm{NC}$ and DC groups. The difference was considered to be significant when ${ }^{* * *} \mathrm{P}<0.0001,{ }^{* *} \mathrm{P}<0.001,{ }^{*} \mathrm{P}<0.05$ when compared to Normal control group and ${ }^{*} \mathrm{P}<0.0001$, ${ }^{\mathrm{b}} \mathrm{P}<0.001,{ }^{\mathrm{c}} \mathrm{P}<0.05$ when compared to Diabetic control group

Table 2: Effect of S. cumini and its combination with acarbose on Mucin content ( $\mu \mathrm{g} / \mathrm{gm})$, Total Proteins ( $\mathrm{mg} / \mathrm{ml})$, SOD (U/mg of protein), CAT (U/mg of protein) observed in Indomethcin induced gastric ulcer model. 


\begin{tabular}{|c|c|c|}
\hline Treatment groups & Ulcer Index & Ulcer Score \\
\hline NC & $1.43 \pm 0.10$ & $9.8 \pm 0.70$ \\
\hline DC & $2.9 \pm 0.29$ & $19.3 \pm 0.76$ \\
\hline QE $50 \mathrm{mg}$ & $1.68 \pm 0.07$ & $14.8 \pm 0.55^{*}$ \\
\hline QE $100 \mathrm{mg}$ & $1.47 \pm 0.07^{*}$ & $11.8 \pm 0.06^{* * *}$ \\
\hline Acarbose & $1.88 \pm 0.56$ & $16 \pm 1.2$ \\
\hline S. cumini seed kernel extract & $1.32 \pm 0.8^{*}$ & $10.3 \pm 0.4^{\star * *}$ \\
\hline $\begin{array}{l}\text { Acarbose+ } \\
\text { S. cumini Seed kernel extract }\end{array}$ & $0.95 \pm 0.73^{* *}$ & $8.5 \pm 1.6^{* * *}$ \\
\hline \multicolumn{3}{|l|}{ Ethanol induced ulcer model } \\
\hline Treatment groups & Ulcer Index & Ulcer Score \\
\hline NC & $1.59 \pm 0.12$ & $7.5 \pm 0.6$ \\
\hline DC & $3.04 \pm 0.10$ & $17.1 \pm 0.55$ \\
\hline QE $50 \mathrm{mg}$ & $2.4 \pm 0.02^{\star *}$ & $13.6 \pm 0.73^{\star *}$ \\
\hline QE $100 \mathrm{mg}$ & $1.9 \pm 0.05^{\star * \star}$ & $10 \pm 0.2^{* \star *}$ \\
\hline Acarbose & $2.8 \pm 0.05$ & $15.6 \pm 1.1$ \\
\hline S. Cumini Seed kernel Extract & $1.7 \pm 0.06^{\star \star \star}$ & $8.8 \pm 0.02^{* * *}$ \\
\hline $\begin{array}{l}\text { Acarbose+S. Cumini } \\
\text { Seed kernel extract }\end{array}$ & $1.4 \pm 0.2^{\star \star *}$ & $6.9 \pm 0.3^{\star \star \star}$ \\
\hline
\end{tabular}

Results are Mean \pm SEM of 6 rats in each group. One-way ANOVA followed by Tuckey's test for multiple comparisons was applied for comparing the Parameters with DC group. The difference was considered to be significant when ${ }^{* * *} \mathrm{P}<0.0001$ ${ }^{* *} \mathrm{P}<0.001,{ }^{*} \mathrm{P}<0.05$ when compared to $\mathrm{DC}$

Table 3: Effect of S.Cumini and its combination with Acarbose on Ulcer index and Ulcer score on Diabetic rats. Indomethacin model.

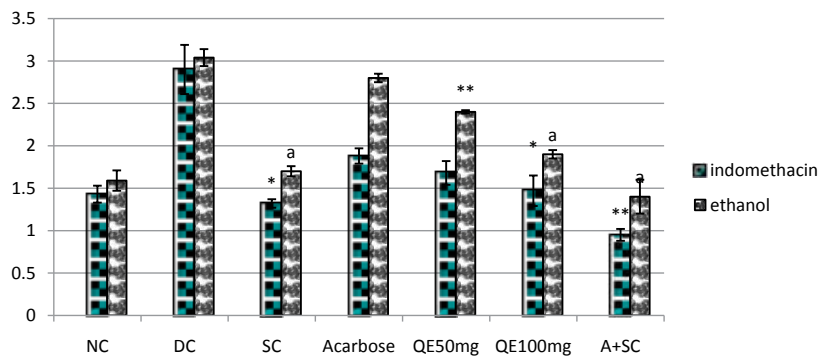

One-way ANOVA followed by Tuckey's test for multiple comparisons was applied for comparing the ulcer index with DC as standard. The difference was considered to be extremely significant when a $\mathrm{P}<0.001$ very significant when ${ }^{* *} \mathrm{P}<0.01$, significant when ${ }^{*} \mathrm{P}<0.05$ when compared to Diabetic control group

Chart 1: Ulcer index graph Indomethcin model and Ethanol model.

Experimental diabetes had shown to increase the propensity to gastric ulceration with an increase in offensive factors namely acid pepsin secretion and lipid peroxidation and decrease in antioxidant status, mucin secretion and mucosal cell shedding, without any effect on cell proliferation [13,40-42].

Diabetic rats exhibited a significant reduction in antioxidant enzyme activity and increased ulcer index values. These parameters regained to normal values when treated with S. cumini and Quercetin. Quercetin has anti oxidant-scavenging activity [43] which delays lipid peroxidation of cell membranes [44] and reduces $\mathrm{cu}^{+}$induced LDL oxidation [45]. S. cumini significantly scavenges free radicals [46] and also has potent antioxidant activity in vitro [16]. S. cumini [18] and Quercetin [47] has proven to protect against the development of diabetic ulcer by restoration of antioxidant enzymes in diabetic rats.

The antiulcer effect of EJE in diabetic rats could be due to decrease in acid-pepsin secretion. There was decrease in propensity to ulceration only in diabetic rats by correcting blood sugar level and reversing the enhanced acid secretion near to normal level. EJE thus, showed significant antiulcer activity in diabetic rats. Hence, Eugenia jambolana could be more effective and economical in diabetes with co-occurring gastric ulcers due to its direct actions both on gastric mucosal offensive and defensive factors or on enhanced acid-pepsin secretion induced by diabetes [18] compared to Acarbose which is decreasing, correcting diabetic parameters only and thus, showing indirect effect on deranged offensive and/or defensive mucosal factors in diabetes.

EJE had significant anti diabetic and anti-ulcer activity in mild diabetes with co-occurring gastric ulcers in rats. However, our results proved that the combined treatment is much effective in treating diabetes induced ulcers than S. cumini alone preventing the progression of diabetic ulcers may be due to their anti-oxidant properties on diabetic stomach. Taken together, the overall observed beneficial effect of low dose combination of Acarbose and S. cumini in preventing the development of diabetic ulcers may be attributed to their direct ulcer protective action and oxidative stress. The ulcer protective effects of Quercetin have been well reported in basic and clinical studies [48]. Therefore quercetin has been employed as a standard drug in the present study. The ulcer protective effect of low dose combination of Acarbose and S. cumin observed in the present study was slightly superior to the effect produced by quercetin in ameliorating diabetes induced ulcerogenic stimuli.

On the basis of the above discussion, it may be concluded that the concurrent administration of S. cumini and Acarbose at low doses may have prevented the development of diabetes induced ulcerogenic stimuli by decreasing the gastric oxidative stress, and providing the direct gastro protective action. In addition, their low dose combination strategy may provide synergistic ulcer protective effect against diabetic ulcerogenic stimuli. Therefore, long-term clinical studies demonstrating the rationale of low dose combination of Acarbose and S. cumini in curing diabetic ulcerogenic stimuli. Our present study proved effectiveness in the combined effect of Syzygium cumini seed kernel extract with oral hypoglycemics in diabetes induced increase in susceptibility to ulcerogenic stimuli.

\section{Acknowledgement}

We express our gratitude to Dr. Premkumar N, Dean, Krupanidhi College of Pharmacy, Bangalore, Karnataka, India for his inspiration and support for this study.

\section{References}

1. Pietzsch M, Theuer S, Haase G, Plath F, Keyser M, et al. (2002) Results of systematic screening for serious gastrointestinal bleeding associated with NSAIDs in Rostock hospitals. Int J Clin Pharmacol Ther 40: 111-115.

2. Boehme MW, Autschbach F, Ell C, Raeth U (2007) Prevalence of silent gastric ulcer, erosions or severe acute gastritis in patients with type 2 diabetes mellitus-a cross-sectional study. Hepatogastroenterology 54: 643-648.

3. Masuda H, Inoue S, Arakawa H, Koizumi K, Kubo N (1976) Peptic ulcer in diabetes mellitus. Gastroenterol Jpn 11: 1-4

4. Goldin E, Ardite E, Elizalde JI, Odriozola A, Panés J, et al. (1997) Gastric mucosal damage in experimental diabetes in rats: role of endogenous glutathione. Gastroenterology 112: 855-863

5. Korolkiewicz R, Tashima K, Kubomi M, Kato S, Takeuchi K (1999) Increased susceptibility of diabetic rat gastric mucosa to food deprivation during cold stress. Digestion 60: 528-537.

6. Tashima K, Fujita A, Takeuchi K (2000) Aggravation of ischemia/reperfusioninduced gastric lesions in streptozotocin-diabetic rats. Life Sci 67: 1707-1718. 
Citation: Jonnalagadda A, Maharaja KK, Prem Kumar N (2013) Combined Effect of Syzygium cumini Seed Kernel Extract with Oral Hypoglycemics in Diabetes Induced Increase in Susceptability to Ulcerogenic Stimuli. J Diabetes Metab 4: 236. doi:10.4172/2155-6156.1000236

7. Brzozowska I, Targosz A, Sliwowski Z, Kwiecien S, Drozdowicz D, et al. (2004) Healing of chronic gastric ulcers in diabetic rats treated with native aspirin, nitric oxide (NO)-derivative of aspirin and cyclooxygenase (COX)-2 inhibitor. $J$ Physiol Pharmacol 55: 773-790.

8. Perdichizzi G, Bottari M, Pallio S, Fera MT, Carbone M, et al. (1996) Gastric infection by Helicobacter pylori and antral gastritis in hyperglycemic obese and in diabetic subjects. New Microbiol 19: 149-154.

9. Takehara K, Tashima K, Takeuchi K (1997) Alterations in duodenal bicarbonate secretion and mucosal susceptibility to acid in diabetic rats. Gastroenterology 112: $418-428$.

10. Tashima K, Korolkiewicz R, Kubomi M, Takeuchi K (1998) Increased susceptibility of gastric mucosa to ulcerogenic stimulation in diabetic rats--role of capsaicin-sensitive sensory neurons. Br J Pharmacol 124: 1395-1402.

11. Iwai K, Kim MY, Onodera A, Matsue H (2004) Physiological effects and active ingredients of Viburnum dilatatum Thunb fruits on oxidative stress. Biofactors 21: $273-275$

12. Hung CR (2005) Effect of lysozyme chloride on betel quid chewing aggravated gastric oxidative stress and hemorrhagic ulcer in diabetic rats. World $J$ Gastroenterol 11: 5853-5858.

13. Mohan Kumar M, Joshi MC, Prabha T, Dorababu M, Goel RK (2006) Effect of plantain banana on gastric ulceration in NIDDM rats: role of gastric mucosal glycoproteins, cell proliferation, antioxidants and free radicals. Indian J Exp Bio 44: $292-299$

14. Kumar A, llavarasan R, Jayachandran T, Deecaraman M, Kumar MR, et al (2008) Anti-inflammatory activity of Syzygium cumini seed. Afr J Biotechno 7: $941-943$.

15. Bhuiyan MS, Mia MY, Rashid MA (1996) Antibacterial principles of the seeds of Eugenia jambolana. Bangladesh Journal of botany 25: 239-241.

16. Zhang LL, Lin YM (2009) Antioxidant tannins from Syzygium cumini fruit. Afr $J$ Biotechnol 8: 2301-2309.

17. Indira G, Mohan R (1993) Jamun Fruits, National Institute of Nutrition. Indian Council of Medical Research 34-37.

18. Chaturvedi A, Bhawani G, Agarwal PK, Goel S, Singh A, et al. (2009) Antidiabetic and antiulcer effects of extract of Eugenia jambolana seed in mild diabetic rats: study on gastric mucosal offensive acid-pepsin secretion. Indian J Physiol Pharmacol 53: 137-146.

19. Kumar NP, Annamalai AR, Thakur RS (2009) Antinociceptive property of Trigonella foenum graceum in high fat diet fed/low dose streptozotocin induced diabetic neuropathy in rats. Pharmacology online 2: 24-36.

20. Broca C, Gross R, Petti P, Sauvaire Y, Manteghetti M, et al. (1999) 4-Hydroxyisoleucine Experimental evidence of its insulinotropic and antidiabetic properties. Am J Physiol Endocrinol Metab 277: E617-E623.

21. Sima AA, Chakrabarti S (1992) Long-term suppression of postprandial hyperglycemia with acarbose retards the development of neuropathies in BB/ W-rat. Diabetologia 35: 325-330.

22. Jose JK, Kuttan G, George J, Kuttan R (1997) Antimutagenic and anticarcinogenic activity of Emblica officinalis. J Clin Biochem Nutr 22: 171-176.

23. Prabha T, Dora Babu M, Priyambada S, Agrawal VK, Goel RK (2003) Evaluation of Pongamia pinnata root extract on gastric ulcers and mucosal offensive and defensive factors in rats. Indian J Exp Biol 41: 304-310.

24. Majumdar B, Ray Chaudhuri SG, Ray A, Bandyopadhyay SK (2003) Effect of ethanol extract of Piper betle Linn leaf on healing of NSAID-induced experimental ulcer--a novel role of free radical scavenging action. Indian J Exp Biol 41: 311-315

25. Lowry CH, Roosebrough NJ, Farr AL, Randall RJ (1951) Protein measurement with the folin phenol reagent. J Biol Chem 193: 265-275.

26. Erich F, Elastner (1976) Inhibition of nitrite formation from hydroxyl ammonium chloride. A simple assay for super oxide dismutase. Anal Chem 70: 616-620.

27. Link EM (1988) The mechanism of $\mathrm{pH}$-dependent hydrogen peroxide cytotoxicity in vitro. Arch Biochem Biophys 365: 362-372.

28. Nguyen KT, Ritz D, Gu JQ, Alexander D, Chu M, et al. (2006) Combinatorial biosynthesis of novel antibiotics related to daptomycin. Proc Natl Acad Sci U S A 103: $17462-17467$

29. Brzozowski T, Konturek PC, Konturek SJ, Kwiecién S, Pajdo R, et al (1998) Involvement of endogenous cholecystokinin and somatostatin in gastroprotection induced by intraduodenal fat. J Clin Gastroenterol 27: S125-S137.

30. Ajeigbe KO, Olaleye SB, Oladejo EO, Olayanju AO (2011) Effect of folic acid supplementation on oxidative gastric mucosa damage and acid secretory response in the rat. Indian J Pharmacol 43: 578-581.

31. Martin JP Jr (1990) Assays for superoxide dismutase based on autoxidation of hematoxylin. Methods Enzymol 186: 220-227.

32. Stevens MJ, Obrosova I, Cao X, Van Huysen C, Greene DA (2000) Effects of DL-alpha-lipoic acid on peripheral nerve conduction, blood flow, energy metabolism, and oxidative stress in experimental diabetic neuropathy. Diabetes 49: $1006-1015$

33. Srinivasan K, Viswanad B, Asrat L, Kaul CL, Ramarao P (2005) Combination of high-fat diet-fed and low-dose streptozotocin-treated rat: a model for type 2 diabetes and pharmacological screening. Pharmacol Res 52: 313-320.

34. Sakai M, Oimomi M, Kasuga M (2002) Experimental studies on the role of fructose in the development of diabetic complications. Kobe J Med Sci 48: 125136.

35. Reed MJ, Meszaros K, Entes LJ, Claypool MD, Pinkett JG, et al. (2000) A new rat model of type 2 diabetes: the fat-fed, streptozotocin-treated rat. Metabolism 49: 1390-1394.

36. Brian L, Mealey DD Diabetes Complications

37. Ahmad M, Qureshi R, Arshad M, Khan MA, Zafar M (2009) Traditional Herba Remedies Used for the Treatment of diabetes From District Attock (Pakistan). Pak J Bot 41: 2777-2782.

38. Shinde J, Taldone T, Barletta M, Kunaparaju N, Hu B, et al. (2008) Alphaglucosidase inhibitory activity of Syzygium cumini (Linn.) Skeels seed kernel in vitro and in Goto-Kakizaki (GK) rats. Carbohydr Res 343: 1278-1281.

39. Jeong SM, Kang MJ, Choi HN, Kim JH, Kim JI (2012) Quercetin ameliorates hyperglycemia and dyslipidemia and improves antioxidant status in type 2 diabetic db/db mice. Nutr Res Pract 6: 201-207.

40. Joshi MC, Dorababu M, Prabha T, Kumar MM, Goel RK (2004) Effects of Pterocarpus marsupium on NIDDM-induced rat gastric ulceration and mucosal offensive and defensive factors. Indian J Pharmacol 36: 296-302.

41. Joshi MC, Mohan Kumar M, Prabha T (2007) Status of mucosal offensive and defensive factors in pylorus ligatcd-induced gastric ulceration in NIDDM rats vis-à-vis plantain banana. J Nat Rem 7: 111-117.

42. Dorababu M, Joshi MC, Bhawani G, Mohan Kumar M, Chaturvedi A, et al. (2006) Effect of aqueous extract of neem (Azadirachta indica) leaves on offensive and defensive gastric mucosal factors in rats. Indian $\mathrm{J}$ Physio Pharmacol 50: 241-249.

43. Yoshizumi M, Tsuchiya K, Suzaki Y, Kirima K, Kyaw M, et.al. (2002) Quercetin glucuronide prevents VSMC hypertrophy by angiotensin II via the inhibition of JNK and AP-1 signaling pathway. Biochem Biophys Res Commun 293: 458-

44. Begum AN, Terao J (2002) Protective effect of quercetin against cigarette tar extract-induced impairment of erythrocyte deformability. J Nutr Biochem 13 265-272.

45. Janisch KM, Williamson G, Needs P, Plumb GW (2004) Properties of quercetin conjugates: modulation of $L D L$ oxidation and binding to human serum albumin. Free Radic Res 38: 877-884

46. Benherlal PS, Arumughan C (2007) Chemical composition and in vitro antioxidant studies on Syzygium cumini fruit. J Sci Food Agric 87: 2560-2569.

47. Meyers KJ, Rudolf JL, Mitchell AE (2008) Influence of dietary quercetin on glutathione redox status in mice. J Agric Food Chem 56: 830-836.

48. González-Segovia R, Quintanar JL, Salinas E, Ceballos-Salazar R, AvilesJiménez $F$, et al. (2008) Effect of the flavonoid quercetin on inflammation and lipid peroxidation induced by Helicobacter pylori in gastric mucosa of guinea pig. J Gastroenterol 43: 441-447. 